\title{
As indicações dos organismos internacionais para as políticas nacionais de educação infantil: do direito à focalização'
}

Rosânia Campos"

\section{Resumo}

0 objetivo deste artigo é analisar os discursos presentes em documentos elaborados por organismos internacionais e governos locais que orientam as políticas voltadas para a educação infantil, com base na concepção de educação como política pública, projeto de governo sob responsabilidade do Estado e direito de todos. A partir do referencial analítico de políticas desenvolvido por Roger Dale, concentramos nossas análises nos textos de diferentes documentos produzidos, sobretudo, pela UNESCO e pela UNICEF. 0 objetivo foi identificar as indicações desses organismos para a educação infantil e suas implicações na efetivação da política local. As análises demonstram que o deslocamento interpretativo da questão social no contexto latino-americano embasa a orientação, recorrente nos documentos, de adoção da educação infantil como estratégia de combate à pobreza e, desse modo, como uma via para promover a equidade social. A repercussão de tal indicação nas políticas locais para a educação infantil, especialmente no que concerne à universalização desse direito, é alarmante, visto que as análises apontam um movimento de ampliação de perspectivas conservadoras e excludentes que acabam reforçando a segmentação da educação das crianças menores de 6 anos.

\section{Palavras-chave}

Política pública para educação - Educação infantil - Políticas sociais - Pobreza - Organismos internacionais.
I- Agradecimento especial ao grupo de estudo e pesquisa sobre educação infantil na América Latina, principalmente à Profa. Dra. Roselena Fátima Campos.

II- Universidade da Região de Joinville, Joinville, SC, Brasil. Contato: rosaniacampos@univille.br 


\section{The international organisms' directions for national policies of early childhood education: from the right to focusing}

Rosânia Campos"

\begin{abstract}
The objective of this article is to analyze the discourses present in documents produced by international organisms and local governments which direct, above all, the policies of early childhood education on the basis of a conception of education as public policy, as government project, under the responsibility of the State, and as a right for everyone. Based on the analytical framework of policies developed by Dale (2004), we focus our analyses on texts of various documents produced mainly by UNESCO and by UNICEF. The objective here was that of identifying the directions of these organisms for early childhood education and their implications for the actual implementation of local policies. The analysis reveals that the interpretive shift of social issues observed in the Latin American context gives support to the direction, recurrent in the documents, of adopting early childhood education as a strategy to tackle poverty and, in so doing, promoting social equity. The repercussions of such directions in local policies for early childhood education, particularly with respect to the universalization of this right, are alarming, since the analyses point to a movement of expansion of conservative and excluding perspectives that end up reinforcing the segmentation of the education of children younger than six.
\end{abstract}

\section{Keywords}

Public policy for education - Early childhood education - Social policies - Poverty - International organisms.
I-Special thanks to the group for study and research on early childhood education in Latin America, especially to Prof. Dr. Fatima Campos Roselena. II- Universidade da Região de Joinville, Joinville, SC, Brazil.Contact: rosaniacampos@univille.br 
Neste artigo, a partir das indicações presentes em documentos oriundos de organismos internacionais e governamentais, objetivamos analisar as políticas locais ${ }^{1}$ de educação das crianças pequenas, políticas estas que, segundo nossa pesquisa, apontam a educação infantil como estratégia de combate à pobreza e de promoção da equidade. Com base na concepção de educação infantil como direito de todas as crianças e como meio de promover a democratização da educação, procuramos tanto discutir as implicações da concepção defendida por organismos internacionais para efetivação desse direito no atual contexto, quanto analisar as repercussões de tais concepções na elaboração e na execução das políticas voltadas para a educação das crianças menores de 6 anos.

Nas últimas décadas, foi notória a emergência das discussões que versam sobre as crianças e seus direitos, sendo esse inclusive o tema de diferentes conferências e reuniões internacionais e regionais. Dentre os direitos aí referidos, o direito à educação, sobretudo à educação infantil, configurou-se como uma questão fundamental para os governos locais. Esse fato nos instiga a questionar: o que configurou essa centralidade na criança e na infância? E por que especificamente a educação infantil se tornou objeto de intervenção? Por que diferentes organismos internacionais concentraram vários estudos e indicações aos países em relação a esse nível educativo? Para responder a essas questões, buscamos compreendê-las dentro do contexto de reforma do Estado e da própria reforma educacional posta em ação a partir da década de 1990 na América Latina.

Nesse sentido, podemos observar que, após as reformas estruturais empreendidas nas últimas décadas do século XX, as desigualdades sociais foram ampliadas, gerando tanto um incremento da pobreza quanto o surgimento dos denominados novos pobres. Tal fato obrigou os Estados a buscarem alternativas para contornar a situação e garantir a governabilidade, todavia,

1- Neste texto, quando se faz menção a governos locais e região, trata-se de referência aos países que compõem a América Latina e o Caribe. sem tomar necessariamente como base o preceito da ampliação dos direitos sociais. Assim, a educação ganha uma centralidade estratégica, associada a uma nova lógica econômica. Seguindo essa lógica, a educação é proclamada por diferentes organismos e governos, nos anos 1990, como eixo da produtividade com equidade, o que torna necessário, segundo os documentos analisados, garantir a oportunidade de acesso e manter um padrão mínimo de qualidade de aprendizagem a fim de promover a equidade pretendida. Essa indicação foi recorrente nas recomendações dos organismos internacionais e das agências financiadoras na década de 1990.

Entretanto, como observa Gentili (2005, p. 41), o termo equidade

aparece como uma redefinição do conceito de igualdade, substituindo e restringindo o alcance da educação pública, em consonância com o desenvolvimento de políticas focalizadas.

Dito de outro modo, a equidade não pode ser compreendida como sinônimo de igualdade; antes, ela se fundamenta na ideia de igualdade de oportunidades, ou seja, na necessidade de haver condições iguais de acesso às oportunidades de realização socioeconômica para todos os membros de uma comunidade política, ideia esta defendida como o instrumento mais legítimo para se alcançar a justiça social (COSTA; KERSTENETZKY, 2005). Assim, a partir da lógica da equidade, as desigualdades geradas seriam desigualdades justas, ${ }^{2}$ visto que emergiriam num contexto onde as distribuições igualitárias de oportunidades estariam presentes. Nesse processo, a educação teria papel fundamental na distribuição de oportunidades e assim, como já mencionado, seria uma indicada estratégia para amenizar as disparidades sociais.

2- Conforme Kerstenetzky (2002, p. 652) "desigualdades justas são aquelas que, resultando da distribuição igual de liberdades e oportunidades (justas), promovem a melhoria da situação dos menos favorecidos". 
Essa ênfase na educação como estratégia de alívio da pobreza e de promoção da equidade organiza-se a partir da lógica das políticas redistributivas compensatórias, afastando-se da ideia de políticas redistributivas estruturais. As causas estruturais da pobreza não são atacadas, e o que se fomenta é o desenvolvimento de políticas compensatórias focalizadas (CAMPOS, 2008). Em consequência, há uma

reorientação da universalidade para a operação de diferentes programas estratégicos e compensatórios da assistência focalizada na linha da pobreza segundo diferentes “públicos alvo". (IVO, 2004, p. 59)

A partir dessa lógica, vários projetos e programas foram iniciados na América Latina e no Caribe, sempre definindo metas e propondo ações e orientações para os países.

É importante destacar que entendemos que as orientações dos organismos internacionais e/ou das agências financiadoras não podem ser compreendidas como ações diretas do contexto econômico-político sobre o Estado; antes, são interações complexas em que

países diferentes interpretarão este conjunto de variáveis de formas diferentes, em consonância com as suas tradições de política social e educativa, [...] e a sua situação na economia mais ampla. (DALE, 1994, p. 116)

Em outras palavras, as orientações presentes nos diferentes documentos não podem ser estudadas como ações lineares e diretas que ocorrem sem resistências ou processos de ressignificação. Entretanto, resguardada essa questão, tais orientações merecem análise, bem como os novos conceitos introduzidos por meio de projetos/planos e agenda.

Assim, a partir do referencial analítico de políticas desenvolvido por Roger Dale (1994) e denominado agenda globalmente estruturada, estudamos principalmente os documentos produzidos pela UNESCO e pela UNICEF, entre os quais podemos citar: Sintesis regional de indicadores de la primera infancia (UNESCO, 2004); Informe de seguimiento de la EPT en el mundo: bases sólidas: atención y educación de la primera infancia (UNESCO, 2007); Proyecto regional de educación para América Latina y el Caribe (UNESCO, 2002); Modelo de acompañamiento-apoyo, monitoreo y evaluación para América Latina y el Caribe (UNESCO, 2002); Situação mundial da infância 2007: mulheres e crianças: o duplo dividendo da igualdade de gênero (UNICEF, 2007); Pobreza infantil en América Latina y el Caribe (CEPAL; UNICEF, 2010); Metas educativas 2021: la educación que queremos para la generación de los Bicentenarios (OEI, 2010).

0 ponto comum entre esses documentos são suas indicações para a educação das crianças, de modo que é possível observar, a partir da década de 1990, a emergência de novos marcos regulatórios para a educação infantil. Já na década de 2000, as análises evidenciam uma indicação crescente da educação infantil como importante estratégia no combate à pobreza. Em outras palavras, a educação infantil se torna rapidamente uma medida paliativa para aliviar os resultados de políticas econômicas que se fundamentam na ideia de gastos mínimos na área social.

Outro aspecto também percebido é a indicação para uma organização da educação das crianças de 0 a 6 anos segmentada pela idade: para os menores de 3 anos, as indicações se pautam pela lógica de proteção, nutrição e educação das famílias; diferentemente, para as crianças maiores de 4 anos, as indicações ainda são pensadas tendo em vista a escolaridade futura. Com isso, observamos uma ratificação da antiga dicotomia presente no modelo da creche e da pré-escola, que marcou a educação infantil também no Brasil e que sempre foi objeto de críticas por parte de pesquisadores, professores e movimentos sociais. Essa indicação ganha novos contornos ao considerarmos que recentemente no Brasil foi aprovada a lei de obrigatoriedade da educação para crianças a partir de 4 anos.

Com base nessas considerações, organizamos o presente artigo discutindo, inicial- 
mente, como a categoria pobreza passa a ser definida no contexto atual; em seguida, nossa atenção é direcionada para as repercussões dessa nova concepção de pobreza nas políticas sociais. Além disso, o modo como os documentos anunciam a educação infantil a partir dessa nova conceituação é outro ponto de análise. Finalizamos com algumas considerações e reflexões acerca do tema.

Da marginalidade à incapacidade: conceituação da pobreza na América Latina

No chamado período desenvolvimentista, o debate sobre a questão social na América Latina, de acordo com Ugá (2011), organizava-se a partir da discussão sobre a marginalidade. Isto é, no auge do período desenvolvimentista, a questão social dos países periféricos era discutida a partir dos fundamentos do funcionalismo, base da teoria da modernização. Seguindo essa perspectiva, o processo de urbanização e industrialização latino-americano implicava rupturas e desarticulações que repercutiam na organização social, gerando desequilíbrios sociais e econômicos. Como consequência, deflagrava-se um processo de ajustamento recíproco que mantinha o todo social integrado. No entanto, essa nova situação estrutural não é atingida por todas as partes da sociedade simultaneamente, o que justificaria as desigualdades sociais (UGÁ, 2011).

No caso da América Latina, as análises se pautavam por um dualismo social formado pela coexistência de um setor tradicional, entendido como atrasado, rural, e de um setor moderno marcado pelo progresso, pela industrialização e pela urbanização. Tal perspectiva dualista definia o marginal em contraposição ao integrado, ou seja: os grupos considerados marginais seriam aqueles em situação de atraso, exclusão, fora da chamada cultura urbana. E como tal, sob essa lógica, os setores marginais, não participantes da população, seriam gradativamente integrados. Nesse sentido, a existência da marginalidade é entendida, pela teoria da modernização, como fenômeno transitório que, por um lado, evidencia a persistência do tradicional no processo de desenvolvimento do moderno e, por outro, poderia ser resolvido pela assimilação dos “desajustes” pelo próprio processo de modernização. (UGÁ, 2011, p. 128)

Seguindo essa teoria, o subdesenvolvimento e o desenvolvimento

eram no fundo a mesma coisa, isto é: momentos constitutivos da mesma realidade - a economia capitalista industrializada -, eles só poderiam ser diferenciados mediantes critérios quantitativos, os únicos adequados para situar uma economia neste ou naquele grau da escala evolutiva. (MARINI, 1994, tradução nossa)

Em outras palavras, as teorias desenvolvimentistas concebiam o desenvolvimento e o subdesenvolvimento como níveis de um mesmo processo. E com base na ideia de escala evolutiva, o subdesenvolvimento era considerado um estágio anterior ao desenvolvimento. De modo similar, as camadas marginalizadas da sociedade correspondiam a uma situação transitória, um momento de passagem entre uma sociedade conservadora e retrógrada para uma sociedade moderna, industrializada e suficiente por si só para garantir a correção dos desequilíbrios e das desigualdades sociais (MARINI, 1994). Nesse contexto, a industrialização foi a grande tônica da década de 1950, tornando-se a ideologia dominante e a matriz por excelência das políticas sociais.

No entanto, segundo Carcanholo (2008, p. 253) o que esse tipo de perspectiva

não consegue captar é que desenvolvimento e subdesenvolvimento são fenômenos qualitativamente diferenciados e ligados tanto pelo antagonismo como pela 
complementaridade, ou seja, que, embora sejam situações antagônicas, os dois fenômenos pertencem à mesma lógica/dinâmica de acumulação de capital em escala mundial.

A crise e a estagnação econômica observadas na década seguinte na América Latina acabaram revelando as características perversas assumidas pela industrialização. Esse cenário exigiu novas teorizações referentes às questões sociais. Entre as teorias políticas então desenvolvidas, encontram-se as abordagens culturalistas, que enfatizam comportamentos e incapacidades dos sujeitos em se apropriarem dos padrões culturais da sociedade moderna. Contudo, segundo Ugá (2011), tais teorias não superaram o âmbito da perspectiva funcionalista, fundamentando-se na concepção de uma sociedade dual. E em nenhuma dessas discussões, no entanto, como destaca Telles (2006), suscitou-se um debate público sobre justiça social e igualdade evidenciando as iniquidades inscritas na trama social. Pelo contrário,

a pobreza aparece sempre como sinal do atraso, pesado tributo que o passado legou ao presente e que envergonha um país que se acostumou a pensar ser o "país do futuro". (TELLES, 2006, p. 85)

Essas concepções transformam a pobreza em "resíduo que escapou à potência civilizadora da modernização e que ainda tem que ser capturado e transformado pelo progresso" (TELLES, 2006, p. 85). Todavia, os anos se passaram e a sociedade que se fez moderna e prometeu a modernidade não conseguiu traduzir os direitos proclamados em parâmetros mais igualitários de ação. Nesse processo, observamos que a partir de 1980 as questões sociais da América Latina passaram a ser aprofundadas e expandidas, e os discursos foram deslocados a fim de explicar e compreender o fenômeno, não mais se fundamentando na teoria da marginalidade. A questão social passa a ser expressa a partir de uma ideia de pobreza (UGÁ, 2011), e tal discurso ganha força na década de 1990, num debate fortemente influenciado por economistas.

Nesse novo contexto latino-americano, a centralidade das discussões é pautada por duas preocupações centrais sobre a pobreza, quais sejam: a necessidade de mensurar a pobreza e de definir medidas para combatê-la. 0 debate é deslocado da arena política - e, portanto, das orientações éticas intrínsecas ao âmbito da justiça social - para a esfera da normatividade técnica. De acordo com o Banco Mundial (1990, p. 27), a pobreza pode ser compreendida como a "incapacidade de atingir um padrão de vida mínimo”. Tal padrão de vida mínimo é avaliado pelo consumo, e a incapacidade aí referida remete a duas questões: oportunidades econômicas e prestação de serviços sociais. Assim, os governos devem dirigir suas ações nesses dois campos de modo focal (UGÁ, 2004).

Nessa concepção, o investimento em capital humano é um dos meios mais importantes para reduzir a pobreza. Ainda de acordo com Ugá (2004, p. 59):

a ideia presente seria, portanto, que, ao educar-se mais, o indivíduo torna-se mais apto a competir com os outros por um emprego melhor no mercado e, consequentemente, a obter uma renda maior.

Em um cenário marcado pelo holocausto social, como diz Borón (2004), governos e organismos internacionais proclamam a necessidade da realização de um ajuste com rosto $h u$ mano (CRONIA et al., 1987, apud CORAGGIO, 1996). A busca de novas bases de legitimação e de maior eficácia no enfrentamento da crise econômica e política na América Latina fez com que os organismos internacionais se empenhassem na construção de um novo paradigma, sustentado na concepção de desenvolvimento humano e não mais na de desenvolvimento econômico. Nas palavras de Coraggio (1996, p. 22), esse novo paradigma "poderia levar a uma uniformização em nível mundial de esquemas 
conceituais, sistemas de informações e políticas”. Exemplifica tal orientação a publicação da CEPAL e da UNESCO, de 1990, intitulada Educação e conhecimento: eixo da transformação produtiva com equidade. 0 documento explicita princípios e estratégias que posteriormente não apenas orientaram as ações das comissões internacionais e intergovernamentais, mas também fundamentaram diferentes projetos e programas, ${ }^{3}$ sob a coordenação de vários organismos na região. Trata-se, então, de reafırmar a economia de mercado e apontar para a necessidade de desenvolver um capitalismo competitivo na região, mas refuta-se a ideia de competitividade espúria, introduzindo-se a de equidade. Nesse processo, ganham força as políticas focais com objetivo de combate à pobreza. Além disso, como já citado, a educação torna-se foco privilegiado, sendo apontada como imprescindível no rompimento dos ciclos de pobreza e na consolidação da equidade social.

É nessa lógica que a educação infantil ganha sua centralidade, em especial, a partir de 2000 , como chave para expansão das capacidades humanas das pessoas pobres. Isso porque, segundo os documentos analisados, quanto mais cedo a criança é educada, maiores serão suas oportunidades de desenvolvimento psicofísico e social; em outras palavras, é fundamental investir na expansão das capacidades humanas das pessoas pobres. Faz-se importante, no entanto, ressaltar que o conceito de capacidade humana, embora seja mais abrangente do que o de capital humano, também não pressupõe e tampouco defende a existência de um Estado que garanta os direitos sociais. Pelo contrário, a defesa é de um Estado caridoso que deverá atuar apenas nos segmentos mais pobres (UGÁ, 2004). Assim, a presença do Estado somente seria necessária em um primeiro momento,

3- Para aprofundar esta discussão é indicado o trabalho intitulado Educação infantil e organismos internacionais: uma análise dos projetos em curso na América Latina e suas repercussões no contexto nacional. (CAMPOS, 2008). no sentido de aumentar as capacidades dos pobres, para, em um segundo momento, quando estes indivíduos já estiverem capacitados, o Estado se tornaria desnecessário. (UGÁ, 2004, p. 60)

Nessa perspectiva, a pobreza é compreendida como decorrente de incapacidade individual, sendo os pobres entendidos como sujeitos com privação de capacidades básicas, as quais seria função do Estado suprir, isto é, ele deveria garantir para os pobres serviços sociais básicos, pois com mais educação e saúde tais indivíduos estariam mais capacitados e livres de suas privações. De acordo com Campos (2012, p. 82), nesse contexto emergem novos discursos sobre

a "infantilização da pobreza", associados às estratégias de focalização da educação nos chamados segmentos vulneráveis da população, reatualizam antigas práticas de educação compensatória, criam novos dispositivos de controle social sobre as crianças e suas famílias, conformando, em sua essência, o sentido atual dado Educação Infantil na região.

Cresce também a defesa da promoção de políticas sociais seletivas e focais, colocando em xeque a concepção de universalidade e valorizando o princípio da focalização como dotado de superioridade democrática, uma vez que respeita às individualidades e às diferenças das pessoas. As repercussões desses discursos são visíveis, sobretudo sob o ponto de vista epistemológico, nas políticas e nos programas voltados para as crianças menores de 3 anos, sendo indicado organizar esse nível educativo a partir de educação em tempo integral fundamentada, de modo especial, nos conhecimentos da neurociência e da psicologia cognitiva (CAMPOS, 2012). Além desse aspecto, a concepção da educação infantil como estratégica no combate à pobreza resulta em sua concepção como uma política focal e em uma privatização de direitos sociais. Nas palavras de Ivo (2003, p. 9), tais indicações implicam 
reconversão do tratamento da questão social separada da institucionalidade da proteção social. Isto significa uma clara separação entre proteção e assistência e uma estratégia de desvinculação da assistência enquanto direitos sociais, reconvertendo questões políticas em questões técnicas.

\section{Educação infantil no contexto das políticas focais}

Sob nossa perspectiva de análise, a educação infantil, principalmente aquela destinada às crianças menores de 3 anos, encontra-se em um momento delicado em relação à própria consolidação de sua função. As indicações presentes nos documentos e planos governamentais revelam um afastamento da concepção de educação infantil como um direito social, um serviço social de interesse público, um modo de democratizar o acesso às formas simbólicas, ao universo dos saberes socialmente construídos e das grandes obras-primas da humanidade (LAVAL, 2004). Esse afastamento se revela ainda mais grave quando retomamos a origem da educação infantil em nosso país.

No Brasil, a educação da infância surge como uma política assistencial associada ao processo civilizatório que teve por base as necessidades individuais e não coletivas, evidenciando as responsabilidades individuais $\mathrm{e}$ não a questão do direito social. A concepção de educação infantil como estratégia civilizatória e assistencial retira-a da universalidade inclusiva e acaba por conferir-lhe um papel de compensar carências, isto é, ela acaba sendo uma forma de agir sobre os efeitos da pobreza, mas não sobre suas causas.

Essa concepção é ratificada por políticas sociais e estratégias governamentais ao longo do século XX, resultando na atribuição, às instituições de educação infantil, de um caráter de provisoriedade emergencial ou, ainda, de substitutas temporárias da figura materna. No campo cientifico, tal período histórico foi marcado pela ascensão de estudos e pesquisas que versavam sobre desenvolvimento infantil, relação mãe-bebê, função da educação, necessidades emocionais das crianças, aspectos psicológicos presentes nos processos de aprendizagem, evolução da linguagem humana, entre outros aspectos, conferindo novas defınições e funções àquelas instituições. Esses estudos, que alcançaram grande repercussão após a II Grande Guerra e que não ocorrem separados de seu próprio contexto socioeconômico, conferiram à educação infantil nos países capitalistas ocidentais um papel muito específico, haja vista que em tais países predominava a defesa da família nuclear e da relação mãe-bebê como ideais. Estudos predominantemente realizados no âmbito da psicologia - provenientes principalmente dos Estados Unidos e da Inglaterra - consideravam a separação ou privação da criança do convívio diário e constante com a mãe como responsável por danos severos no desenvolvimento infantil.

Entre outros fatores, a repercussão desses discursos contribuiu para a retração da oferta no atendimento educacional às crianças pequenas, acentuando ainda mais a marca das instituições de educação infantil como paliativas: um mal necessário, uma alternativa para uma necessidade circunstancial. Além disso, tal repercussão colaborou e legitimou ações e planos governamentais que colocaram a educação infantil à margem dos sistemas educacionais e secundarizados no que se refere aos investimentos.

Em vários países, a expansão desse serviço só foi retomada no final da década de 1960 e no início da década de 1970, sendo especialmente fomentada pelas "reivindicações e propostas de movimentos sociais urbanos, entre eles o movimento feminista" (ROSEMBERG, 1995, p. 92). No Brasil, a expansão observada nos anos de 1970 deu-se no âmbito do governo militar, mas não a partir do princípio da universalidade de "conotação eminentemente pública, cidadã e igualitária/ equânime" (PEREIRA; STEIN, 2010, p. 107); antes, tal expansão fez parte das estratégias 
governamentais de obtenção de consenso, pela via do discurso de atenção aos carentes.

Difundia-se então, não apenas no Brasil, mas também na América Latina, a ideia de mudança social via educação, delegando-se à educação infantil o papel de compensar as carências culturais das crianças pobres e, assim, criar condições de acesso às oportunidades educativas, promovendo a equalização social. Desse modo, as instituições de educação infantil, por criarem condições para o futuro sucesso escolar, serviriam de ponte para atravessar as diferenças existentes entre as classes sociais (KRAMER, 1995).

Data desse período, segundo Rosemberg (2001), a entrada de organizações internacionais como a UNESCO e a UNICEF no âmbito da educação infantil. Sua inserção tanto na América Latina como em países africanos implicou não apenas incentivos e políticas de indução à expansão desse nível de atendimento educacional via instituições não-formais, mas também uma mudança no modus operandi desses organismos, que ampliaram seu raio de atuação para além do tradicional binômio saúde-nutrição, envolvendo-se em projetos educativos destinados à infância e à juventude.

É importante registrar também que a expansão da educação infantil no Brasil, pautada tanto em uma perspectiva política de compensar desigualdades sociais, quanto na representação da criança e da infância pobre como carentes ou privadas culturalmente, não apenas produziu desdobramentos no modelo de expansão adotado - "lidar pobremente com a pobreza" (FRANCO, 1995, p. 179) -, mas também induziu a um tipo e um modo de organização das instituições, bem como influenciou nas práticas educativas que tiveram como destinatários as crianças pequenas. Prevaleceram modos de atendimentos organizados a partir de baixos custos, com transferência de responsabilidades e de execução de ações para as comunidades, o que resultou em instituições com baixa qualidade e com baixo potencial para um desenvolvimento integral e adequado das crianças. Em termos de políticas públicas, essa ampliação do atendimento ficou muito mais incorporada às políticas assistenciais do que às educativas. $\mathrm{Na}$ contestação dessas iniciativas, os movimentos reivindicatórios passaram a defender a ampliação de vagas para educação das crianças de 0 a 6 anos, com base no direito universal à educação (HADDAD, 2006).

Em consonância com a crescente consciência social acerca da educação infantil como direito das crianças, estudos e pesquisas avançaram também na perspectiva de afırmação da especificidade dos processos educativos destinados a esse nível de ensino. Desse modo, repensar a educação das crianças pequenas em espaços coletivos tornou-se um desafio também para pesquisadores e estudiosos da área. Avanços conceituais e metodológicos possibilitaram a construção de um conjunto de conhecimentos que propiciaram o estabelecimento de rupturas com uma concepção de educação infantil antecipatória ou preparatória à escolarização obrigatória, ou ainda como compensatória das carências culturais. Todavia, essa tarefa não tem sido fácil, na medida em que implica rupturas também em outros universos, por exemplo, no papel da mulher e sua função como mãe; no próprio papel do Estado, que deverá assumir a tarefa; e na concepção de infância e de criança, que deixa de ser reconhecida por suas faltas e passa a ser defendida como sujeito de direitos.

Tal mudança de conceber a infância é também observada na concepção da função da educação infantil, a qual, de forma ascendente, tem sido reconhecida por estudos e pesquisas como um espaço coletivo educativo que deve garantir, de acordo com Faria (2000, p. 75):

a) o direito à infância sem antecipar a escolaridade do ensino fundamental (no entanto, sem esquecer da necessidade de levar em conta a continuidade destes segmentos de educação das crianças principalmente daquelas de 0 a 10 anos); b) um ambiente educativo que contemple a indissociabilidade 
do cuidado/educação das crianças pequenas; c) o respeito aos direitos fundamentais das crianças.

Seguindo esse raciocínio, a educação das crianças em instituições precisa ser organizada não para o individualismo, o conformismo e a submissão; pelo contrário, necessitamos superar a dupla alienação da infância e garantir o direito das crianças de serem crianças, de descobrir e conhecer o mundo por meio de brincadeiras, atividades, trocas e, enfim, por meio das mais variadas relações com adultos, objetos e demais crianças (FARIA, 2000).

Ao afırmarmos a educação infantil como um direito de todas as crianças, independentemente de idade, classe econômica ou período escolar que frequentam, colocamo-nos na perspectiva de uma superação da visão assistencial historicamente vinculada a esse segmento educativo, aquela que com arrogância "humilha para depois oferecer o atendimento como dádiva, como favor aos poucos selecionados para o receber" (KUHLMANN JÚNIOR, 2000, p. 54). Assim compreendida, a educação infantil torna-se uma tarefa pública socialmente compartilhada, que se

reflecte em políticas públicas que respeitem os direitos das crianças e associam-se, frequentemente, às políticas sociais voltadas para a família. (ROCHA, 2002, p. 68)

Não obstante, tal reconhecimento da especificidade ou particularidade social da infância e as diversas leis e declarações em favor de seus direitos não se traduziram em sinônimo de uniformidade ou garantia de boas condições de vida a todas as crianças. Esse aparente descompasso entre o proclamado e o efetivado é visível quando observamos que, se

por um lado, as crianças têm ganho visibilidade na presença pública e conseguido lugar na agenda das preocupações políticas e sociais, de outra parte, os problemas de dependência, segregação, exploração e pobreza que as afetam parecem não só mais visíveis, como também maiores em variedade e extensão. (MUÑOZ, 2006, p. 64, tradução nossa)

Conceber as crianças como sujeitos sociais concretos e as problemáticas que constituem a infância na contemporaneidade como resultantes de determinações sociais, econômicas, políticas e culturais historicamente construídas leva-nos a postular que a defesa de sua educação como meio para garantir sua educabilidade posterior e, assim, como mediação necessária para a ruptura do chamado ciclo vicioso da pobreza constitui-se em um discurso de cunho ideológico que tanto mantém elementos das antigas práticas políticas assistenciais e filantrópicas, quanto lança mão de dispositivos de legitimação calcados nas ideias de direito e justiça social. As indicações presentes nos documentos se pautam, sobretudo, pela lógica assistencial, paliativa e residual, abstendo-se da possibilidade de intervir no nível das estruturas que geram essas disparidades entre as classes sociais (MUÑOZ, 2006).

Tendo como pressuposto essas considerações, entendemos que urge recolocar o debate referente à função da educação infantil no campo da política, de modo que o Estado, como sujeito político, tenha seu papel reafirmado como responsável e mediador para que a relação entre direitos e justiça social se estabeleça. Isto é: faz-se necessário discutir a difusão de políticas sociais seletivas e/ou focalizadas, bem como a lógica que fundamenta a ideia de que a educação infantil, se não pode atender a todos, pelo menos deve atender àqueles que precisam mais. Para além desse aspecto, outro fato que nos chama atenção é a significativa segmentação que podemos observar no investimento público em relação ao atendimento das crianças menores de 6 anos, o que evidencia ainda mais a perspectiva focal que está sendo dada a essa política. 
Segundo Campos (2012), é visível a crescente institucionalização da educação infantil em nossa região, decorrente tanto das obrigações assumidas pelos chefes de Estado a partir dos documentos de que são signatários, quanto da própria pressão social. Entretanto, ainda de acordo com a autora, a responsabilidade pública é mais visível nos segmentos etários de 4 e 5 anos, esquivando-se do atendimento às crianças menores de 3 anos. Essa observação pode ser verificada nos dados de atendimento, os quais evidenciam uma aproximação com a universalização da educação de 4 e 5 anos e um crescimento pífio no segmento de 0 a 3 anos. Soma-se a esses dados o recorte da obrigatoriedade da educação na América Latina e recentemente no Brasil: dos dezessete países latino-americanos, dois não possuem a educação infantil como obrigatória; em quatro, essa obrigatoriedade é iniciada aos 3 anos; e, nos demais, a exemplo do Brasil, a obrigatoriedade ocorre a partir de 4 ou 5 anos (CAMPOS, 2012).

A centralidade nos anos mais próximos da escolaridade é justificada pela prática focalista que se fundamenta na lógica da fragmentação e do curto prazo, pois entende-se que a antecipação da entrada das crianças na educação infantil garantirá maior sucesso em seu processo escolar futuro. Nas palavras do Banco Mundial (1990), assim se aumenta o capital humano, sobretudo o dos pobres, oportunizando que estes possam competir com outros por empregos melhores no mercado. De modo similar, as indicações para as crianças menores de 3 anos referem-se a ações voltadas para a estimulação cognitiva, como afirma o documento final das Metas educativas 2021 (OEI, 2010, p. 98, tradução nossa): “o desenvolvimento cerebral dos primeiros anos afeta tanto a saúde mental e física, quanto o comportamento pelo resto da vida".

Ainda segundo esse documento:

É imprescindivel que se garantam as condições básicas de alimentação e saúde das crianças pequenas, a provisão de estimulação variada, o apoio às famílias para que atendam às necessidades de desenvolvimento e de educação de seus filhos, e a incorporação progressiva das crianças em situações educativas organizadas que contribuam para sua maturidade e aprendizagem. (OEI, 2010, p. 98, tradução nossa)

Essa dicotomia presente nas indicações e o reforço na necessidade de serem ações, sobretudo, voltadas para as crianças pobres reforçam o papel da educação infantil como estratégia focalizada para o combate à pobreza. Na definição de dois objetivos distintos para a educação infantil - um para as crianças menores de 3 anos, outro para as crianças de 4 e 5 anos -, observamos um desvio do compromisso da política social para a satisfação das necessidades sociais e a ênfase na “adoção de soluções técnicas e pontuais, tidas como inovadoras, aparentemente neutras e facilmente controláveis" (PEREIRA; STEIN, 2010, p. 106). Sob a égide da equidade, tal focalização afasta o debate relativo à justiça e à igualdade, de modo que a repercussão para a educação infantil é no perigoso recrudescimento de antigas práticas e formas de organização da área.

Consideramos, ainda, que a universalização do direito, quando subjugada à lógica da focalização, produz um efeito perverso, pois acaba por incluir excluindo, ou seja, por meio da disjunção entre quantidade e qualidade (expansão sem qualidade), e também do encolhimento do direito de outros, no caso das crianças de 0 a 3 anos. Em outras palavras, segundo Campos (2012, p. 99), a adoção desse tipo de estratégia acaba por

inaugurar novas formas de segmentação e de focalização de políticas, que longe de distribuir com "equidade" as "oportunidades educacionais”, criam novas formas de discriminação e de subalternização. 


\section{Considerações finais}

Ao empreendermos a análise dos documentos provenientes de organismos internacionais em ação na região, pudemos observar inúmeras indicações e/ou orientações para a educação das crianças pequenas na América Latina. Entretanto, é importante destacar, como já o fizemos anteriormente, que as orientações indicadas pelos organismos internacionais, segundo entendemos, vão sendo apropriadas pelos Estados e incorporadas nas políticas educativas locais, num processo que não ocorre de maneira linear, direta e sem a participação estatal. De igual modo, compreendemos que mesmo que seja possível observar uma mudança nos papéis do Estado nas últimas décadas como consequência das reformas estruturais implantadas, essa mudança não pode ser considerada como sinônimo de perda de força ou desaparecimento de sua ação. Pelo contrário, sob nossa perspectiva de análise, o Estado, continua presente em sua função reguladora em determinadas áreas, como a educação, e em seu papel fundamental na mediação exigida para a consolidação do processo de globalização. Dessa forma, faz-se necessário compreender dialeticamente a relação entre as indicações dos organismos internacionais e a apropriação destas pelos governos locais, e não simplesmente conceber esse processo como uma mera submissão dos governos locais aos ditames das grandes potências econômicas.

A partir dessa perspectiva de análise, desenvolvemos o presente trabalho e observamos que, como discutido no início do texto, em especial na última década do século XX, a criança e seus direitos começaram a figurar como tema em diferentes conferências e reuniões internacionais e regionais. Em todas essas ações, o direito à educação sempre se configurou como imprescindível. No entanto, quando analisamos a evolução das matrículas nos últimos anos, observamos que as metas estipuladas em diferentes reuniões e documentos estão longe de serem atingidas, o que evidencia uma distância entre o proclamado e o efetivado. Ao mesmo tempo, a análise dos documentos derivados de tais reuniões e conferências mostra que a concepção preponderante é da educação infantil como uma boa opção paliativa para aliviar os resultados de políticas econômicas que se fundamentam na ideia de gastos mínimos na área social (CAMPOS, 2008).

Outro aspecto comum observado nas indicações para a organização da educação das crianças de 0 a 6 anos é a já mencionada segmentação pela idade, que acaba por ratificar a antiga dicotomia presente no modelo da creche e da pré-escola.

Para além disso, a ideia de focalização das ações do Estado - justificada pela lógica da seletividade dos gastos sociais - a fim de garantir que os subsídios públicos cheguem aos cidadãos necessitados acaba por suplantar o direito de todas as crianças à educação infantil. Dito de outro modo, o direito social é convertido em uma prestação individualizada, não compondo a esfera das políticas públicas que possuem como pressuposto o atendimento a todas as pessoas, inclusive aos grupos vulneráveis. 0 termo aí utilizado, inclusive, não é equivalente a preferencial ou exclusivo. Assim, o poder público, que deveria organizar sistemas adequados para garantir a participação de todos nos bens da coletividade e uma melhor distribuição desses bens - princípio a partir do qual as políticas públicas são forjadas -, volta-se para o desenvolvimento de diferentes programas estratégicos e compensatórios da assistência focalizada. Desse modo, em nome da inclusão social, do alívio da pobreza, da maior eficácia e eficiência das ações estatais, observamos a emergência de uma nova segmentação social que resulta, ao final, em exclusão justamente da população que, de acordo com os discursos oficiais, deveria ser incluída na sociedade. De acordo com o que discutimos, as políticas focais não oportunizam aos sujeitos integração efetiva na sociedade; pelo contrário, acabam reforçando a assistência, no sentido mais tradicional, e mantendo tal população na dependência. 
De acordo com Pereira e Stein (2010, p. 116), esse tipo de política não é e nunca foi caminho de inclusão social, uma vez que tem como

principal objetivo excluir e manter excluído o máximo possível de demandantes da proteção do Estado para aliviar as despesas governamentais como áreas consideradas "improdutivas".

As ações focais não têm o poder de alterar as relações sociais estabelecidas, nem se propõem a fazê-lo. Pelo contrário, elas reforçam antigas relações de clientelismo, conformando os beneficiados em sujeitos de gratidão, e substituem o acesso universal - direitos sociais, bens públicos - pelo acesso seletivo, o qual possibilita determinar tanto quem irá receber, quanto quem irá ser o provedor dos benefícios (CAMPOS, 2008).

Assim, entendemos que os avanços observados nas políticas destinadas à educação das crianças pequenas - sobretudo o reconhecimento desse nível educativo como direito são frágeis e que muitas das conquistas - como a unicidade entre creche e pré-escola - ainda não foram consolidadas. A esse fato somam-se aspectos como: as indicações dos organismos internacionais; a pressão social por abertura de mais vagas na educação infantil; a obrigatoriedade da educação a partir de 4 anos; a indicação no Plano Nacional de Educação (BRASIL, 2011), em sua estratégia 1.4 para

estimular a oferta de matriculas gratuitas em creches por meio de concessão de certificação de entidade beneficente de assistência social na educação.

Considerando tais aspectos em conjunto, podemos vislumbrar a possibilidade de entrarmos em um novo ciclo expansivo, via tercei- ro setor, subvencionado com recursos públicos, mas agora não mais de assistência e sim de educação. No entanto, ainda se segue uma lógica fortemente marcada pela seletividade e pela segregação, uma vez que a defesa do direito universal das crianças à educação infantil é acompanhada pela discussão da necessidade de se atender, senão a todos, pelo menos àqueles que precisam mais. Temos hoje no país, tal como procuramos evidenciar, um projeto de educação infantil pública e gratuita fomentado pelas inúmeras iniciativas internacionais e perpassado pela necessidade de restringir o direito às crianças mais pobres, tendo em vista a disponibilização de recursos do Estado.

Esse cenário, associado à concepção de educação como forte estratégia de combate à pobreza, incorre em sérios riscos, assim como evidencia um equívoco: o da concepção de pobreza como

fruto de circunstâncias que afetam determinados indivíduos (ou famílias) desprovidos de recursos que o qualifiquem para o mercado de trabalho. (TELLES, 1993, p. 13)

A pobreza não é apenas indicativo de carências, mas, antes, indicativo de uma condição de privação de direitos que acaba por definir e formar modelos de socialização (TELLES, 1993).

Assim, discutir a educação infantil como direito é retomar conceitos esvaziados e/ou ressignificados, como o de cidadania. Nesse sentido, é mister lembrar que cidadania social, "em sua essência, sempre esteve relacionada à garantia de direitos e não com programas compensatórios" (UGÁ, 2004, p. 61). Entender a educação infantil por essa perspectiva é reivindicar um direito de todas as crianças, independentemente de sua renda, direito que deve ser garantido simplesmente pelo fato de serem cidadãos. 


\section{Referências}

BANCO MUNDIAL. Relatório sobre o desenvolvimento mundial: a pobreza. Washington: Banco Mundial, 1990.

BORÓN, Atílio. Os "novos Levitãs" e a polis democrática: neoliberalismo, decomposição estatal e decadência da democracia na América Latina. In: SADER, Emir; GENTILI, Pablo (Orgs.). Pós-neoliberalismo II: que Estado para que democracia? 4. ed. Petrópolis: Vozes, 2004. p. 7-67.

BRASIL. Lei $n^{0}$ 10.172, de 9 de janeiro de 2001. Aprova o Plano Nacional de Educação e dá outras providências. Diário Oficial da União, Brasília, DF, 10 jan. 2001. Disponível em: <http://portal.mec.gov.Br/arquivos/pdf/L10172.pdf>. Acesso em: 20 dez. 2012.

CAMPOS, Rosânia. Educação infantil e organismos internacionais: uma análise dos projetos em curso na América Latina e suas repercussões no contexto nacional. Tese (Doutorado), Universidade Federal de Santa Catarina, Florianópolis, 2008.

CAMPOS, Roselane F. "Política pequena" para as crianças pequenas? Experiências e desafios no atendimento das crianças de 0 a 3 anos na América Latina. Revista Brasileira de Educação, São Paulo, v. 17, n. 49, p. 81-105, jan./abr. 2012.

CARCANHOLO, Marcelo Dias. Dialética do desenvolvimento periférico: dependência, superexploração da força de trabalho e política econômica. Revista de Economia Contemporânea, Rio de Janeiro, v. 12, n. 2, p. 247-272, maio/ago. 2008.

CEPAL; UNESCO. Educação e conhecimento: eixo da transformação produtiva com eqüidade. Brasília: IPEA/CEPAL/INEP, 1990.

CEPAL; UNICEF. Pobreza infantil en América Latina y el Caribe. Santiago, 2010.

CORRAGIO, José Luis. Desenvolvimento humano e educação: o papel das ONGs latinoamericanas na iniciativa da educação para todos. São Paulo: Cortez; Instituto Paulo Freire, 1996.

COSTA, Ana Czeresnia; KERSTENETZKY, Célia Lessa. Desigualdade intragrupos educacionais e crescimento. Economia e Sociedade, Campinas, v. 14, n. 2, p. 337-364, jul./dez. 2005.

DALE, Roger. A promoção do mercado educacional e a polarização da educação. Educação, Sociedade e Culturas, Porto, n. 2, p. 109-139, 1994.

FARIA, Ana Lucia G. 0 espaço físico como um dos elementos fundamentais para uma pedagogia da educação infantil. In: FARIA, Ana Lucia G.; PALHARES, Marina S. Educação infantil pós-LDB: rumos e desafios. 2. ed. Campinas: Autores Associados, FE/ UNICAMP; São Carlos: Editora da UFSCar; Florianópolis: Editora da UFSC, 2000. p. 67-97.

FRANCO, Maria Aparecida Ciavatta. Lidando pobremente com a pobreza: análise de uma tendência no atendimento a crianças "carentes" de 0 a 6 anos de idade. In: ROSEMBERG, Fúlvia (Org.). Creche. 2. reimp. São Paulo: Cortez, 1995. p. 179-216.

GENTILI, Pablo. La educación en las cumbres de las Américas: su impacto en la democratización e los sistemas educativos. Ensayos \& Investigaciones del Laboratorio de Políticas Públicas, Buenos Aires, n. 1, 2005.

HADDAD, Lenira. Políticas integradas de educação e cuidado infantil: desafios, armadilhas e possibilidades. Cadernos de Pesquisa, São Paulo, v. 36, set./dez. 2006.

IV0, Anete Brito Leal. Políticas sociais de combate à pobreza nos anos 1990: novas teses, novos paradigmas. In: SUPERINTENDÊNCIA DE ESTUDOS ECONÔMICOS E SOCIAIS DA BAHIA. Pobreza e desigualdades sociais. Salvador: SEI, 2003. p. 7-28. (Série Estudos e Pesquisas, 63). Disponível em: <www.sei.ba.gov.br>. Acesso em: 10 jan. 2013.

IVO, Anete Brito Leal. A reconversão do social: dilemas da redistribuição no tratamento focalizado. São Paulo em Perspectiva, São Paulo, v. 18, n. 2, p. 57-67, 2004.

KERSTENETZKY, Célia Lessa. Por que se importar com a desigualdade. DADOS - Revista de Ciências Sociais, Rio de Janeiro, v. 45, n. 4, p. 649-675, 2002.

KRAMER, Sônia. A política do pré-escolar no Brasil: a arte do disfarce. 5. ed. São Paulo: Cortez, 1995. 
KUHLMANN JÚNIOR, Moysés. Educação infantil e currículo. In: FARIA, Ana Lucia G.; PALHARES, Marina S. Educação infantil pósLDB: rumos e desafios. 2. ed. Campinas: Autores Associados, FE/UNICAMP; São Carlos: Editora da UFSCar; Florianópolis: Editora da UFSC, 2000. p. 99-112.

LAVAL, Christian. A escola não é empresa: o neoliberalismo em ataque ao ensino público. Tradução de Maria Luiza M e Carvalho e Silva. Londrina: Planta, 2004.

MARINI, Ruy Mauro. La crisis del desarrollismo. 1994. Disponível em: <http://www.marini-escritos.unam.mx/026_crisis_ desarrollismo_es.htm>. Acesso em 20 dez. 2012.

MUÑOZ, Louders Gaitán. El bienestar social de la infancia y los derechos de los niños. Política y Sociedad, Madrid, v. 43, n. 1, p. 63-80, 2006.

OEl. Metas educativas 2021: la educación que queremos para la generación de los Bicentenarios. Madrid, 2010.

PEREIRA, Potyara Amazoneida P.; STEIN, Rosa Helena. Política social: universalidade versus focalização. Um olhar sobre a América Latina. In: BOSCHETTI, Ivanete et al. (Orgs). Capitalismo em crise, política social e direitos. São Paulo: Cortez, 2010. p. 106-130.

ROCHA, Eloisa A. C. Infância e educação: delimitações de um campo de pesquisa. Educação, Sociedade e Culturas, Porto, n. 17, p. 67-88, 2002.

ROSEMBERG, Fúlvia. 0 movimento de mulheres e a abertura no Brasil: o caso da creche - 1984. In: (Org.). Creche. 2. reimp. São Paulo, Cortez, 1995.

Avaliação de programas, indicadores e projetos em educação infantil. Revista Brasileira de Educação, São Paulo, n. 16, p. 19-26, jan./abr. 2001.

TELLES, Vera da Silva. Pobreza e cidadania: dilemas do Brasil contemporâneo. Caderno CHR, Salvador, n. 19, p. 8-21, 1993.

Direitos sociais: afinal do que se trata? 2. reimp. Belo Horizonte: Ed. UFMG, 2006.

UGÁ, Viviam Domingues. A categoria "pobreza" nas formulações de política social do Banco Mundial. Revista de Sociologia e Política, Curitiba, n. 23, p. 55-62, nov. 2004.

A questão social como "pobreza": critica à conceituação neoliberal. Curitiba: Appris, 2011.

UNESCO. Modelo de acompañamiento-apoyo, monitoreo y evaluación para América Latina y el Caribe. Havana, 2002a.

Proyecto regional de educación para América Latina y el Caribe (PROLAC). Havana, 2002b.

Oficina Regional de Educación para América Latina y el Caribe (OREALC). Síntesis regional de indicadores de la primera infancia. Santiago, mayo 2004.

Oficina Regional de Educación para América Latina y el Caribe (OREALC). Informe de seguimiento de la EPT en el mundo: bases sólidas: atención y educación de la primera infancia. Paris, 2007.

UNICEF. Situação mundial da infância 2007: mulheres e crianças: o duplo dividendo da igualdade de gênero. Brasília, 2007.

Recebido em: 23.06.2012

Aprovado em: 21.08.2012

Rosânia Campos é doutora em Educação, professora do Programa de Pós-Graduação em Educação da Universidade da Região de Joinville (UNIVILLE), em Santa Catarina. 